\title{
DIREITOS HUMANOS DA MULHER: REFLEXÕES SOBRE VIOLÊNCIA E TRABALHO NO BRASIL
}

\author{
Grasiele Augusta Ferreira Nascimento ${ }^{1}$ \\ Regina Vera Villas Bôas ${ }^{2}$
}

\begin{abstract}
Resumo
O presente artigo apresenta um estudo a respeito dos Direitos Humanos da mulher, especialmente em relação à violência vivenciada na família e na sociedade, à inserção e às discriminações enfrentadas no trabalho. A análise é realizada por meio do método teóricodocumental, com base em dados estatísticos oficiais e na legislação brasileira atual.
\end{abstract}

Palavras-chave: Direitos humanos; violência; trabalho; discriminação; mulher.

\section{HUMAN RIGHTS OF WOMEN: REFLECTIONS ABOUT VIOLENCE AND WORK IN BRAZIL}

\begin{abstract}
This article presents a study on the human rights of women, especially in relation to violence experienced in the family and in society, the insertion and the discrimination faced in the work. The analysis is performed using the theoretical-documentary method, based on official statistical data and current Brazilian legislation.
\end{abstract}

Keywords: Human rights. Violence. Job. Discrimination. Woman.

\section{Introdução}

A participação da mulher na sociedade atual reflete uma trajetória de lutas e conquistas.

\footnotetext{
${ }^{1}$ Pós-doutora em Democracia e Direitos Humanos pela Universidade de Coimbra/Ius Gentium Conimbrigae (2014), Doutora em Direito pela Pontifícia Universidade Católica de São Paulo (2002), Diretora Operacional do Centro Universitário Salesiano de São Paulo (UNISAL). Professora e Pesquisadora do Programa de Mestrado em Direito do Centro Universitário Salesiano de São Paulo (UNISAL), Professora Assistente Doutora da Faculdade de Engenharia de Guaratinguetá (FEG/UNESP). Líder do grupo de pesquisa "Minorias, discriminação e efetividade de direitos" (CNPq/Unisal). Membro da Academia de Letras de Lorena (ALL).

${ }^{2}$ Pós-Doutora em Democracia e Direitos Humanos pela Universidade de Coimbra - Ius Gentium Conimbrigae, Doutora em Direito Civil pela Pontifícia Universidade Católica de São Paulo (2002) e Doutora em Direito Difusos e Coletivos pela Pontifícia Universidade Católica de São Paulo (2009). Professora titular da Pontifícia Universidade Católica de São Paulo, Professora do Programa de Mestrado em Direito do Centro Universitário Salesiano de São Paulo (UNISAL), Avaliadora do Instituto Nacional de Estudos e Pesquisas Educacionais Anísio Teixeira. Membro do grupo de pesquisa "Minorias, discriminação e efetividade de direitos" (CNPq/Unisal).
} 
Em virtude de uma cultura tradicionalmente patriarcal, o homem assumia o papel de provedor da família, assim como os papéis políticos na comunidade; enquanto a mulher era responsável pelo cuidado da família, da casa e da educação dos filhos.

Com as mudanças culturais e familiares ocorridas ao longo dos anos, a participação da mulher na sociedade foi ganhando significativo impulso, gerando uma série de normas de proteção na legislação nacional e internacional, em busca da igualdade de direitos e de oportunidades em relação aos homens.

Apesar da evolução desta participação na sociedade, infelizmente a mulher ainda enfrenta diversas formas de violência e discriminações, tanto no âmbito familiar, como no âmbito laboral.

A finalidade da presente pesquisa, a qual será realizada por meio do método teóricodocumental, é apresentar reflexões a respeito da concretização das normas de proteção às mulheres no Brasil, especificamente em relação à violência e à inserção no trabalho.

\section{Violência contra a mulher}

O fenômeno da violência contra a mulher é cada vez mais discutido na sociedade, pois atinge todas as classes sociais e impede que seja alcançada a efetiva igualdade e a dignidade humana previstas na Constituição da República Federativa do Brasil.

Para entendermos o fenômeno da violência contra a mulher, contudo, é necessário compreendermos o conceito de gênero. Nas palavras de Maria de Fátima Araújo, o termo "gênero", na sua acepção gramatical, designa indivíduos de sexos diferentes (masculino/feminino) ou coisas sexuadas, mas, na forma como vem sendo usado, nas últimas décadas, pela literatura feminista, adquiriu outras características: enfatiza a noção de cultura, situa-se na esfera social, diferentemente do conceito de "sexo", que se situa no plano biológico, e assume um caráter intrinsecamente relacional do feminino e do masculino. (2005, p. 42).

No campo das ciências sociais, portanto, podemos entender que sexo e gênero são termos diferentes: enquanto "sexo" é a categoria biológica, "gênero" é a expressão culturalmente determinada da diferença sexual: o feminino e o masculino. E a partir desta divisão, também se percebem as relações de poder. 
“A partir da construção social e cultural do que é masculino e feminino, estabelecida a partir das diferenças percebidas entre homens e mulheres, surgem as desigualdades de gênero. (AZEREDO; MEINERO, 2015, p. 77). Assim sendo, a desigualdade de gênero é identificada não apenas pela violência e discriminação contra a mulher, atingindo, também, toda a ideia do que é feminino, incluindo a discriminação contra travestis, transexuais e homossexuais.

A violência e discriminação de gênero é fruto do comportamento da própria sociedade patriarcal, na qual os homens, desde meninos, são estimulados a desenvolver condutas agressivas, que revelam a sua dominação e o seu poder; enquanto as mulheres são estimuladas a serem doces e maternais. Não que ser doce e maternal seja um problema e que as mulheres devam se comportar de maneira diferente, muito pelo contrário, mas que a docilidade não seja sinônimo de fragilidade e de submissão ao homem.

De fato, as vantagens dadas aos homens na sociedade, desde meninos, estimulam a desigualdade entre homens e mulheres, que irão refletir em toda a sociedade, proporcionando diversos problemas relacionados à violência, inclusive no âmbito familiar, assim como a discriminação da mulher em diversos setores, como no trabalho.

“A violência contra a mulher é uma das principais expressões da dominação feminina. Ela reforça a ideia de que as mulheres são objetos pertencentes aos homens e que o exercício da agressão e da humilhação é normal. As mulheres são submetidas a uma soma de dominação e exploração" (AZEREDO; MEINERO, 2015, p. 79). E não podemos concordar com a ideia de que a mulher é cúmplice, pelo fato de aceitar as desculpas do agressor, pois o consentimento com a agressão somente existiria se ambas as partes desfrutassem do mesmo poder, o que não acontece na relação de gênero: é a cultura da superioridade masculina. Para se ter uma ideia, dados da violência no Brasil apontam que 106.093 (cento e seis mil e noventa e três) mulheres foram mortas de 1980 a 2013, a maioria delas na última década.

Pelos registros do SIM, entre 1980 e 2013, num ritmo crescente ao longo do tempo, tanto em número quanto em taxas, morreu um total de 106.093 mulheres, vítimas de homicídio. Efetivamente, o número de vítimas passou de 1.353 mulheres em 1980, para 4.762 em 2013, um aumento de 252\%. A taxa, que em 1980 era de 2,3 vítimas por 100 mil, passa para 4,8 em 2013, um aumento de 111,1\%. Em 2006 foi sancionada a Lei $\mathrm{n}^{\circ} 11.340$, conhecida como Lei Maria da Penha. (WAISELFISZ, 2015, p. 13) 


\section{DIREITOS HUMANOS DA MULHER: REFLEXÕES SOBRE VIOLÊNCIA E TRABALHO NO BRASIL}

Também em comparação com outros países, os dados estatísticos apontam que a situação da violência contra a mulher no Brasil é alarmante.

Com sua taxa de 4,8 homicídios por 100 mil mulheres, o Brasil, num grupo de 83 países com dados homogêneos, fornecidos pela Organização Mundial da Saúde, ocupa uma pouco recomendável $5^{a}$ posição, evidenciando que os índices locais excedem, em muito, os encontrados na maior parte dos países do mundo. Efetivamente, só El Salvador, Colômbia, Guatemala (três países latino-americanos) e a Federação Russa evidenciam taxas superiores às do Brasil. Mas as taxas do Brasil são muito superiores às de vários países tidos como civilizados: • 48 vezes mais homicídios femininos que o Reino Unido; • 24 vezes mais homicídios femininos que Irlanda ou Dinamarca; • 16 vezes mais homicídios femininos que Japão ou Escócia. Esse é um claro indicador que os índices do País são excessivamente elevados. (WAISELFISZ, 2015, p. 29).

Os índices de estupro também são alarmantes. Em 2014, por exemplo, foram registrados cerca de 47.646 estupros, de acordo com os dados oficiais das secretarias estaduais da Segurança coletados pelo Fórum Brasileiro de Segurança Pública, o que equivale um caso a cada onze minutos, em média, no país. (REIS, 2015).

A triste realidade é que a violência de gênero decorre da cultura patriarcal, pois normalmente é praticada por homens da convivência e confiança da vítima. Neste sentido, significativa proteção à mulher prevista no ordenamento jurídico brasileiro é a Lei 11.340/2006, conhecida como Lei Maria da Penha, que constitui um grande avanço quanto à proteção à mulher no Brasil. De acordo com a introdução do texto aprovado, a referida lei Cria mecanismos para coibir a violência doméstica e familiar contra a mulher, nos termos do art. 226 da Constituição Federal, da Convenção sobre a Eliminação de Todas as Formas de Discriminação contra as Mulheres e da Convenção Interamericana para Prevenir, Punir e Erradicar a Violência contra a Mulher; dispõe sobre a criação dos Juizados de Violência Doméstica e Familiar contra a Mulher; altera o Código de Processo Penal, o Código Penal e a Lei de Execução Penal; e dá outras providências.

Não menos importante é a Lei 13.104/2015, conhecida como a Lei do Feminicídio, a qual alterou o art. 121 do Código Penal, para prever o feminicídio como circunstância qualificadora do crime de homicídio, e o art. 1 o da Lei no 8.072, de 25 de julho de 1990, para incluir o feminicídio no rol dos crimes hediondos. Nos termos da referida lei, caracteriza-se 
feminicídio quando o crime envolve violência doméstica e familiar, ou quando retrata menosprezo ou discriminação à condição de mulher, caracterizando crime por razões de condição do sexo feminino.

A pena do feminicídio é aumentada de $1 / 3$ (um terço) até a metade se o crime for praticado durante a gestação ou nos 3 (três) meses posteriores ao parto; contra pessoa menor de 14 (catorze) anos, maior de 60 (sessenta) anos ou com deficiência; ou na presença de descendente ou de ascendente da vítima.

É importante destacar que a criação da figura penal do feminicídio veio esclarecer que uma pessoa que morreu assassinada não teria morrido nas mesma circunstâncias se não fosse mulher. Trata-se de encarar a violência de gênero e aumentar seu rigor punitivo, na medida importante na intimidação do agressor. (ELUF, 2017, p. 61).

Assim como o Brasil, “14 países da América Latina possuem leis versando o crime de feminicídio: Argentina, Bolívia, Chile, Colômbia, Costa Rica, Equador, El Salvador, Guatemala, Honduras, México, Nicarágua, Panamá, Peru e Venezuela” (ELUF, 2017, p. 62). Contudo, embora as leis acima mencionadas representem a luta contra a invisibilidade da violência, isoladamente não é capaz de evitar a violência e o homicídio de mulheres. Segundo pesquisa realizada pelo IPEA (Instituto de Pesquisa Econômica Aplicada), com a Lei Maria da Penha conseguiu-se reduzir somente cerca de $10 \%$ da taxa de homicídio contra as mulheres dentro das residências. Desta forma, há a necessidade de combinar inúmeras e efetivas políticas públicas além do âmbito criminal/judiciário, estendendo-as para várias áreas, especialmente nas de saúde pública e educação, com o objetivo de materializar os direitos assegurados às mulheres. Entre as ações que podem ser citadas como exemplos, destacamos o Plano Nacional de Políticas para Mulheres (PNPM), que tem como objetivo estabelecer um conjunto de ações envolvendo o governo, os ministérios, as empresas públicas e a sociedade civil; assim como as atividades realizadas pelo Serviço Único de Saúde (SUS), através de práticas de orientação e acompanhamento da saúde da mulher, prestando informações sobre violência e monitorando os casos através de visitas periódicas às residências. (AZEREDO; MEINERO, p. 83-84).

Sem dúvida, a problemática advém de aspectos sociais e culturais, daí necessitando de uma mudança social e cultural. 


\section{Trabalho da mulher}

Outro elemento que é apontado como uma das soluções para a violência é a independência financeira da mulher. A questão da inserção da mulher no mercado de trabalho e o reconhecimento da igualdade de direitos também envolvem aspectos culturais, sociais e de identidade. Assim como nos demais setores, também no trabalho o papel da mulher na sociedade brasileira passou por significativas mudanças ao longo da história. Sua inserção e participação no mercado de trabalho foram marcadas por desigualdades em relação ao trabalho masculino, incluindo diversas formas de exploração e discriminação, como longas jornadas de trabalho, salários inferiores aos dos homens, maiores índices de desemprego e discriminação em relação à maternidade. Apesar da crescente evolução do trabalho feminino e da adoção do princípio da igualdade pela Constituição Federal de 1988, os dados estatísticos ainda apontam significativas diferenças de oportunidades e de salários. Vale destacar que a inclusão da mulher do mercado de trabalho também está relacionada às composições familiares.

Em 2000, por exemplo, as mulheres comandavam 24,9\% dos 44,8 milhões de domicílios particulares existentes no País. Em 2010, essa proporção cresceu para 38,7\% dos 57,3 milhões de domicílios brasileiros, o que representam um aumento de 13,7 pontos percentuais, segundo as Estatísticas de Gênero - Uma análise dos resultados do Censo Demográfico 2010, produzidas pelo Instituto Brasileiro de Geografia e Estatística (IBGE). $(\ldots)$

Nas famílias formadas pelo responsável sem cônjuge e com filho(s), as mulheres foram maioria na condição de responsável $(87,4 \%)$. O critério para definir a pessoa responsável pela família é de que aquela pessoa seja reconhecida como tal pelos demais membros do domicílio. (MAIS, 2017).

Para garantir a igualdade no trabalho, a legislação trabalhista contempla vários dispositivos que protegem o trabalhador contra critérios discriminatórios.

A Constituição Federal de 1988 elencou entre os direitos dos trabalhadores urbanos e rurais, "a proteção do mercado de trabalho da mulher, mediantes incentivos específicos, nos termos da lei" (art. $\left.7^{\circ}, \mathrm{XX}, \mathrm{CF}\right)$. 
$\mathrm{O}$ art. $7^{\circ}, \mathrm{XXX}$, da Constituição Federal, também assegurou proteção contra a discriminação por motivo de sexo, idade, cor ou estado civil, proibindo qualquer diferença de salários, de exercício de funções e de critério de admissão por motivo de sexo, idade, cor ou estado civil.

Em relação à admissão no emprego, a legislação brasileira proíbe a exigência de atestados de gravidez e esterilização, e outras práticas discriminatórias, para efeitos admissionais ou de permanência da relação jurídica de trabalho, protegendo a mulher contra a discriminação em razão da situação familiar, como a gravidez, assegurando o direito à readmissão, com todos os salários do período de afastamento ou a percepção em dobro da remuneração do período de afastamento, corrigida monetariamente e com juros legais.

Contudo, embora seja crescente a participação das mulheres no mercado de trabalho e a diminuição das desigualdades entre homens e mulheres no Brasil, de acordo com a pesquisa de emprego e desemprego realizada pelo convênio DIEESE (Departamento Intersindical de Estatística e Estudos Econômicos), nas Regiões Metropolitanas de Belo Horizonte, Fortaleza, Porto Alegre, Recife, Salvador, São Paulo, e Distrito Federal, no período de 2011-2012, ainda é marcante a discriminação das mulheres no mercado de trabalho no Brasil, uma vez que enfrentam dificuldades não apenas no ingresso em um emprego, mas também para a sua manutenção, sem contar que ainda auferem salários menores do que os homens. (A INSERÇÃO, 2013, p. 1).

Em pesquisa realizada pelo Banco Interamericano de Desenvolvimento (BID), constatou-se que os salários das mulheres no Brasil são aproximadamente $30 \%$ menores que os salários dos homens.

O estudo promoveu a análise de informações domiciliares provenientes de 18 países da região, constatando que as mulheres, os/as negros/as e os/as indígenas recebem salários inferiores aos dos homens brancos na América Latina.

(...) As mulheres latino-americanas ganham menos, mesmo que possuam um maior nível de instrução. Por meio de comparação simples dos salários médios, foi constatado que os homens ganham $10 \%$ a mais que as mulheres. Já quando a comparação envolve homens e mulheres com a mesma idade e nível de instrução, essa diferença sobe para $17 \%$. 
(...) De acordo com a pesquisa, os homens ganham mais que as mulheres em todas as faixas de idade, níveis de instrução, tipo de emprego ou de empresa. A disparidade é menor nas áreas rurais, em que as mulheres ganham, em média, o mesmo que os homens. A menor diferença salarial relacionada a gênero está na faixa mais jovem da população que possui nível universitário, sendo a defasagem mais baixa entre trabalhadores formais e mais alta entre aqueles que trabalham em pequenas empresas.

As diferenças salariais variam muito também entre os 18 países pesquisados. O Brasil apresenta um dos maiores níveis de disparidade salarial. No país, os homens ganham aproximadamente $30 \%$ a mais que as mulheres de mesma idade e nível de instrução, quase o dobro da média da região $(17,2 \%)$, enquanto na Bolívia a diferença é muito pequena. (HOMENS, p. 1, 2017).

Embora o salário percebido pelas mulheres tenha aumentado nos últimos anos, pelo menos no Brasil, ainda é significativamente inferior ao salário dos homens, nas mesmas funções, o que comprova a necessidade de políticas públicas também para a busca da igualdade entre homens e mulheres no trabalho.

Outro problema de significativa importância é a elevada taxa de desemprego das mulheres, que supera a dos homens, e que continua em crescimento.

Segundo os dados da Pesquisa Nacional por Amostra de Domicílios (Pnad Regional) referentes ao primeiro trimestre de 2016 mostram que o desemprego entre as mulheres é muito superior e cresceu mais do que entre os homens. No Brasil, a taxa ficou em 9,5\% para os homens e 12,7\% para as mulheres, uma diferença de 3,2 pontos percentuais. A desocupação entre as mulheres supera também a média nacional para o período, que ficou em $10,9 \%$ - a maior taxa da série histórica, iniciada em 2012. A maior diferença por gênero está na região Norte, onde a taxa de desemprego feminina é 5,4 pontos percentuais maior do que a masculina. As regiões Sul e Sudeste apresentaram a menor diferença (2,9 pontos maior entre as mulheres).

Enquanto a taxa geral entre as mulheres saltou 3,1 pontos percentuais na passagem de um ano e 1,9 ponto percentual na passagem de trimestre, a dos homens saltou 2,9 pontos percentuais e 1,8 ponto nos períodos respectivos. (COSTA, 2016). 
Além das diferenças salariais e do índice elevado de desemprego, a mulher também vivencia outros dissabores no âmbito laboral, ocupando os maiores índices de assédio moral e sexual no trabalho, além de discriminação estética e em relação à maternidade.

\section{Considerações finais}

As conquistas das mulheres, ao longo dos anos, foram inúmeras, tanto em relação à família, quanto à sociedade e ao trabalho.

Contudo, infelizmente, percebe-se que a concretização da igualdade de direitos e de oportunidades esbarra na herança de uma cultura patriarcal, com predomínio do gênero masculino sobre o feminino.

Embora o ordenamento jurídico brasileiro, assim como ocorre nos demais países da América Latina estudados, contemple princípios e normas de proteção à mulher nos diversos setores, entendemos que a problemática advém de aspectos sociais e culturais, daí necessitando de uma mudança social e cultural. Para tanto, faz-se urgente a adoção de políticas efetivas de educação para a igualdade e para a paz de forma urgente, adotadas pelas escolas, famílias e sociedade.

\section{Referências}

A INSERSÃO das mulheres nos mercados de trabalho metropolitanos e a desigualdade nos rendimentos.

Disponível

em: http://www.dieese.org.br/analiseped/2013/2013pedmulhermet.pdf. Acesso em: 10/02/2017.

ARAÚJO, Maria de Fátima. Diferença e igualdade nas relações de gênero: revisitando o debate. Revista Piscologia Clínica. Rio de Janeiro, vol.17, n.2, 2005. Disponível em: http://www.scielo.br/scielo.php?script=sci_arttext\&pid=S0103-56652005000200004.

Acesso em: 10 fev. 2017.

ARAÚJO, Adriane Reis de; FONTENELE-MOURÃO, Tânia (Orgs.). Trabalho de mulher: mitos, riscos e transformações. São Paulo: LTr, 2007.

ARCHENTI, Nélida; TULA, María Inés (Editoras). Mujeres y política em América Latina: Sistemas electorales y cuotas de gênero. Buenos Aires: Heliasta, 2008. 
AZEREDO, Caroline Machado de Oliveira; MAINER, Fernanda Sartor. Reflexões acerca das políticas públicas brasileiras de enfrentamento à violência de gênero. In: VASCONCELOS, Antonio Gomes de; XIMENES, Julia Maurmann. Direitos sociais e políticas públicas. Florianópolis, Conpedi, 2015. Disponível em: http://docplayer.com.br/31434571-Xxiv-congresso-nacional-do-conpedi-ufmg-fumecdomhelder-camara.html

BELEZA, Teresa Pizarro. Direito das mulheres e da igualdade social: a construção jurídica das relações de gênero. Coimbra: Almedina, 2010.

BRITO FILHO, José Cláudio Monteiro de. Discriminação no trabalho. São Paulo: LTr, 2002.

BRUSCHINI, Maria Cristina Aranha. Trabalho e gênero no Brasil nos últimos dez anos. Disponível em: www.scielo.br/pdf/cp/v37n132/a0337132.pdf. Acesso em: 17 abr. 2014.

CALIL, Léa Elisa Silingowschi. História do direito do trabalho da mulher: aspectos históricos-sociológicos do início da República ao final deste século. São Paulo: Ltr, 2000.

CALIL, Léa Elisa Silingowschi. Direito do Trabalho da mulher: a questão da igualdade jurídica ante a desigualdade fática. São Paulo: LTr, 2007.

CANTELI, Paula Oliveira. O trabalho feminino no divâ: dominação e discriminação. São Paulo: LTR, 2007.

COSTA, Daiane. Desemprego é maior e cresce mais entre as mulheres, indica IBGE. Disponível em: http://oglobo.globo.com/economia/desemprego-maior-cresce-mais-entreasmulheres-indica-ibge-19335320. Acesso em: 22 jan. 2017.

COSTA, Florença Ávila de Oliveira; MARRA, Marlene Magnabosco. Famílias brasileiras chefiadas por mulheres pobres e monoparentalidade feminina: risco e proteção. Rev. bras. psicodrama, São Paulo, v. 21, n. 1, 2013 Disponível em $<$ http://pepsic.bvsalud.org/scielo.php?script=sci_arttext\&pid=S010453932013000100011\&l ng=pt\&nrm=iso>. acessos em 01 jun. 2014.

ELUF, Luiza Nagib. Feminicídio. Revista da Caasp. São Paulo, vol. 27, fev/17. Disponível em: http://anyflip.com/oqfm/gceg/basic/51-64. Acesso em: 05 mar. 2017. 
FRANCO FILHO, Georgenor de Sousa. Trabalho da mulher: homenagem a Alice Monteiro de Barros. São Paulo: Ltr, 2009.

GAMBA, Juliane Caravieri Martins; MONTAL, Zélia Maria Cardoso. Trabalho da mulher e a emenda constitucional n. 72/2013. Disponível em: http://www.publicadireito.com.br/artigos/?cod=7b72de504960bfce. Acesso em: 09 maio 2014.

GOLSDAL, Thereza Cristina. Discriminação da mulher no emprego. Curitiba: Gênesis, 2003.

HOMENS, recebem salários 30\% maiores que as mulheres no Brasil. Disponível em: http://www.observatoriodegenero.gov.br/menu/noticias/homens-recebem-salarios30maiores-que-as-mulheres-no-brasil/. Acesso em: 10 han. 2017.

JAKUTIS, Paulo. Manual de estudo da discriminação no trabalho. São Paulo: LTr, 2006.

LIMA, Maria da Glória Malta Rodrigues Neiva de. A proteção da igualdade de gênero no ordenamento jurídico nacional e internacional e os mecanismos asseguratórios. Rev. TRT 9a R. Curitiba a. 35, n.65, Jul./ Dez. 2010, p. 1-72. Disponível em: www.trt9.jus.br. Acesso em: 27 maio 2014.

LUZ, Alex Faverzani da; FUCHINA, Rosimeri. A evolução histórica dos direitos da mulher sob a ótica do direito do Trabalho. Disponível em: http://www.ufrgs.br/nucleomulher/arquivos/artigoalex.pdf. Acesso em: 27 maio 2014.

MAIS mulheres assumem a chefia das famílias, revela pesquisa do IBGE. Disponível em: http://www.brasil.gov.br/economia-e-emprego/2014/10/mais-mulheres-assumem-achefiadas-familias-revela-pesquisa-do-ibge. Acesso em: 20 jan. 2017.

NASCIMENTO, Grasiele Augusta Ferreira (org) Direito das Minorias: proteção e discriminação no trabalho. Campinas: Alínea, 2004.

NASCIMENTO, Grasiele Augusta Ferreira. Proteção contra a discriminação da mulher na relação laboral: questões relevantes enfrentadas pelos ordenamentos jurídicos do Brasil e de Portugal. Lisboa: Chiado, 2015. 
PARTICIPAÇÃO das mulheres brasileiras na política é uma das mais baixas da América Latina e Caribe. Disponível em: https://nacoesunidas.org/participacao-dasmulheresbrasileiras-na-politica-e-uma-das-mais-baixas-da-america-latina-e-caribe/. Acesso em: 12 fev. 2017.

PINHEIRO, Luana; GALIZA, Marcelo; FONTOURA, Natália. Novos arranjos familiares, velhas convenções sociais de gênero: a licença-parental como política pública para lidar com essas tensões. Rev. Estud. Fem., Florianópolis, v. 17, n. 03, dez. 2009.

Disponível

em

<http://educa.fcc.org.br/scielo.php?script=sci_arttext\&pid=S0104026X2009000300013\&lng $=$ pt\&nrm=iso $>$. acesso em 29.mai. 2014.

PIOVESAN, Flávia. Direitos Humanos e o Direito Constitucional Internacional. $6^{\text {a }}$ Ed. São Paulo: Max Limonad, 2004.

PIOVESAN, Flávia. Direitos Humanos e Direito do Trabalho. Atlas: São Paulo, 2010.

PROTEÇÃO da maternidade. Notas da OIT. Trabalho e família. Disponível em: http://www.oitbrasil.org.br/content/nota-4-prote\%C3\%A7\%C3\%A3o-da-maternidade-0.

Acesso em: 12 maio 2014.

QUIRINO, Raquel. Trabalho da mulher no Brasil nos últimos 40 anos. Disponível em: files.dirppg.ct.utfpr.edu.br/ppgte/revistatecnologiaesociedade/rev15/r15_a5.pdf. Acesso em: 17 abr. 2014.

RAMOS, Daniela Peixoto. Pesquisas de usos do tempo: um instrumento para aferir as desigualdades de gênero. Revista Estudos Feministas. Florianópolis, vol 17, n. 3, set/dez 2009. Disponível em: www.scielo.br/pdf/ref/v17n3/v17n3a14. Acesso em: 01 maio 2014.

RAPOSO, Vera Lúcia. Os limites da igualdade: um enigma por desvendar: a questão da promoção da igualdade laboral entre os sexos. In: Questões laborais, A. 11, no 23. Coimbra: Coimbra Editora, 2004. p. 42-80.

REIS, Thiago. $\mathrm{N}^{\circ}$ oficial de estupros cai, mas Brasil ainda tem 1 caso a cada 11 minutos. Disponível em: http://g1.globo.com/politica/noticia/2015/10/n-oficial-de-estupros-cai-masbrasilainda-tem-1-caso-cada-11-minutos.html. Acesso em: 15 jan. 2017. 
RETRATO das desigualdades de gênero e raça. Disponível em: www.ipea.gov.br. Acesso em: 01 maio 2014.

ROJO, Eduardo Caamaño. Mujer, trabalho y derecho. Santiago: Abeledo Perrot, 2011.

ROSA, Waldemir. Sexo e cor: categorias de controle social e reprodução das desigualdades socioeconômicas no Brasil. Dossiê retrato das desigualdades de gênero e raça. Revista Estudos Feministas, Florianópolis, vol 17, n. 3 set/dez 2009. Disponível em: www.scielo.br. Acesso em: 01 maio 2014.

SANTOS, Alberto Silva; ALVES, Aline Cristina. A flexibilização das normas trabalhistas e o impacto no acesso do mercado de trabalho pelas mulheres. Qual o papel dos Direitos Humanos? In: GUIMARÃES, Antônio Marcio da Cunha; GOMES, Eduardo Biachi; LEISTER, Margareth Anne. Florianópolis : FUNJAB, 2013. p. 226-291. Disponível em: http://www.publicadireito.com.br/artigos/?cod=7fc346397dc20225. Acesso em: 10 abr. 2014.

SILVA, Antônio Álvares da. Trabalho da mulher e do menor. In: FRANCO FILHO, Georgenor de Sousa. Trabalho da mulher: homenagem a Alice Monteiro de Barros. São Paulo: Ltr, 2009. Cap. 1, p. 21-73.

SOUZA, Ana Maria Viola; NASCIMENTO, Grasiele Augusta Ferreira (Orgs.). Direito e o Trabalho. Campinas: Alínea, 2009.

TÁRREGA. Maria Cristina Vidotte Blanco; MIRANDA, Carla. Trabalhadoras na reestruturação produtiva do capital: qual Direito? Disponível em: http://www.conpedi.org.br/manaus/arquivos/anais/campos/maria_cristina_tarrega_e_carla _miranda.pdf. Acesso em: 09 maio 2014.

TEODORO, Maria Cecília Máximo; SILVA, Lídia Marina de Souza e. Gravidez no emprego: reflexões sobre a tendência global de proteção ao emprego e ao mercado de trabalho da mulher. In: NASCIMENTO, Grasiele Augusta Ferreira; MAISAILIDIS, Mirta Gladys Lorena Manzo de; SILVA, Lucas Gonçalves da. Direito do trabalho I. Florianópolis :FUNJAB,2013 p. 279-299. Disponível em: http://www.publicadireito.com.br/artigos/?cod=0498b76a320aee7c. Acesso em: 10 Abr. 2014. 
THOME, Candy Florencio. O princípio da igualdade de gênero e a participação das mulheres nas organizações sindicais de trabalhadores. São Paulo: Ltr, 2012.

WAISELFISZ, Julio Jacobo. Mapa da violência 2015: Homicídio de mulheres no Brasil. Disponível em: www.mapadaviolencia.org.br. Acesso em: 02 mar. 2017.

ZIMMERMANN, Silvia Maria; DOS SANTOS, Teresa Cristina Dunka Rodrigues; DE LIMA, Wilma Coral Mendes. O assédio moral e o mundo do trabalho. Disponível em:

http://www.prt12.mpt.gov.br/prt/ambiente/arquivos/assedio_moral_texto.pdf. Acesso em 09 fev. 2014. 